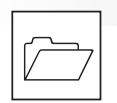

Endokrynologia Polska

DOI: $10.5603 /$ EP.a2020.0067

Volume/Tom 71; Number/Numer 6/2020

ISSN 0423-104X

\title{
Third gender - the clinical image of Morris syndrome
}

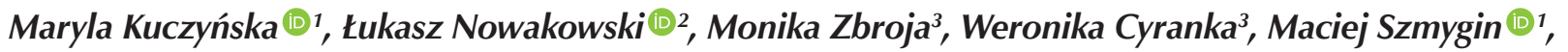 \\ Krzysztof Pyra ${ }^{1}$
}

${ }^{1}$ Department of Interventional Radiology and Neuroradiology, Medical University of Lublin, Lublin, Poland

${ }^{2} 2^{\text {nd }}$ Department of Gynaecology, Medical University of Lublin, Lublin, Poland

${ }^{3}$ Students' Scientific Society at the Department of Interventional Radiology and Neuroradiology, Medical University of Lublin, Lublin, Poland

Key words: complete androgen insensitivity syndrome; disorders of sex development; 46,XY DSD; doppler ultrasonography;

magnetic resonance imaging

Androgen insensitivity syndrome (AIS) occurs with a prevalence of 1:20,000-1:640,000 of male live births, and encompasses a spectrum of disorders that is characterised by the maternal, $\mathrm{X}$-linked recessive mutations of the gene encoding intracellular androgen receptors [1]. Despite 46,XY karyotype, patients exhibit female external sex characteristics. Its most severe form (complete androgen insensitivity, CAIS), initially defined as testicular feminisation syndrome, was extensively described by Morris et al. in 1953 [2]. As a result of complete tissue insensitivity to testosterone, the development of the Wolff duct is ceased. Concurrent activity of the anti-Müllerian hormone (AMH) prevents the development of the Müller duct and its derivate organs. Testicles are usually normally developed, but abnormally located - descended to the inguinal ring; the vagina is short and blind-ended. Neither uterus nor fallopian tubes are found. Testosterone production is normal or minimally elevated as for the normal male range. Gonadotropin (LH mainly) and 17- $\beta$-oestradiol concentrations might be higher than the normal male level $[3,4]$.

Androgen insensitivity syndrome is a rare but important cause of primary amenorrhoea. Counselling the patient should always include not only thorough gynaecological and endocrinological examinations, but also extensive diagnostic imaging (transvaginal ultrasound, magnetic resonance, MR, and computed tomography, CT) to assess the development and possible pathologies of the lower pelvic organs; especially because CAIS diagnosis may be preceded by Mayer-Rokitansky-Küster-Hauser (MRKH) syndrome or gonadal dysgenesis in as many as $10 \%$ of patients [5].
We hereby present a case of a 22-year-old patient with female gender identity, who required gynaecological counselling due to symptoms of mild inflammation. During medical history-taking she reported to be diagnosed with primary amenorrhoea in her adolescence; however, her medical history was incomplete, e.g. lacking genetical consult. The patient could not recall any specific diagnosis, however she was well aware of having hypoplastic uterus and claimed to have normal female karyotype $46, X X$. She had a sexual partner and was sexually satisfied.

General examination revealed reduced pubic and scanty axillary hair. The patient was asked about any depilation in the vulvar region, which was negative. In the gynaecological examination breasts and labia minora were normally developed. There was no visible cervix and the vagina was shortened $(4.5 \mathrm{~cm})$. The clitoris size was normal, and the Quigley scale assessment revealed no virilisation, which is expected for complete androgen insensitivity syndrome. The bimanual examination did not show any pathological resistance within the minor pelvis. Furthermore, uterus and adnexa were not found on palpation. Transvaginal ultrasound indicated no echogenicity characteristic for the uterus, cervix, and adnexa, or their remnants. Due to these findings, the patient was advised to perform hormonal and genetic testing on an outpatient basis. MR was performed to assess lower pelvic organs, which confirmed the absence of uterus and ovaries; it depicted hypoplastic vagina (Fig. 1A, B). In addition, two solid ovoid masses were visible in the inguinal canals, which were primarily described as reactive lymph nodes (Fig. 1C, D), which was consistent with the history of inflammation. 
Table 1. Hormone testing and karyotyping results. Normal ranges are presented in round brackets

\begin{tabular}{lcc}
\hline Hormone testing & & \\
\hline LH $[\mathrm{mlU} / \mathrm{mL}]$ & 44.94 & $(1.9-12.5)$ \\
\hline FSH $[\mathrm{mlU} / \mathrm{mL}]$ & 3.90 & $(2.5-10.2)$ \\
\hline Testosterone* $[\mathrm{ng} / \mathrm{dL}]$ & 422.4 & $(14-76)$ \\
\hline $17-\beta$-oestradiol $[\mathrm{pg} / \mathrm{mL}]$ & 42.3 & $(19.5-144.2)$ \\
\hline Karyotype & $46, \mathrm{XY}$ & \\
\hline
\end{tabular}

LH — luteinising hormone; FSH — follicle-stimulating hormone; * normal female ranges. Laboratory results indicated elevated levels of both luteinising hormone and testosterone, which, along with male karyotype, is consistent with diagnosis of androgen insensitivity

The patient presented for follow-up with the results of genetic and hormonal testing (Tab. 1).

The laboratory results supplemented by the normal male karyotype were consistent with the pattern of complete androgen insensitivity. Transabdominal ultrasound was then performed to further investigate the nature of inguinal masses. It depicted two oval, solid structures in both inguinal canals lacking typical features of reactive lymph nodes (hilum, vascularity pattern). However, scattered/diffuse blood flow signals characteristic for testicles were observed along with tubular structures consistent with epididymis, indicating final diagnosis of cryptorchidism.

The patient was informed about the diagnosis of CAIS and its ramifications. She was advised to undergo bilateral gonadectomy because of the increased risk of malignancy in the abnormally located testicles. After both psychological and psychiatric consultation, the patient decided to join a support group and identified herself as member of the third sex. She withheld consent to surgical and pharmacological (hormone replacement therapy) treatment.

The diagnosis of CAIS requires a complex gynaecological, hormonal, genetic, and diagnostic imaging approach. Although transvaginal scan is a method of choice for the assessment of female reproductive organs, MR enables examination of the entire lower pelvis anatomy, which is crucial when investigating for atypically located, residual, or remnant structures and possible malignancies. Doppler ultrasound offers the unique opportunity to appraise complex vascularity patterns, which together with morphological assessment allows clear differentiation between reactive lymph nodes and testicles. The psychological impact of the diagnosis is another critical point of care in young women with
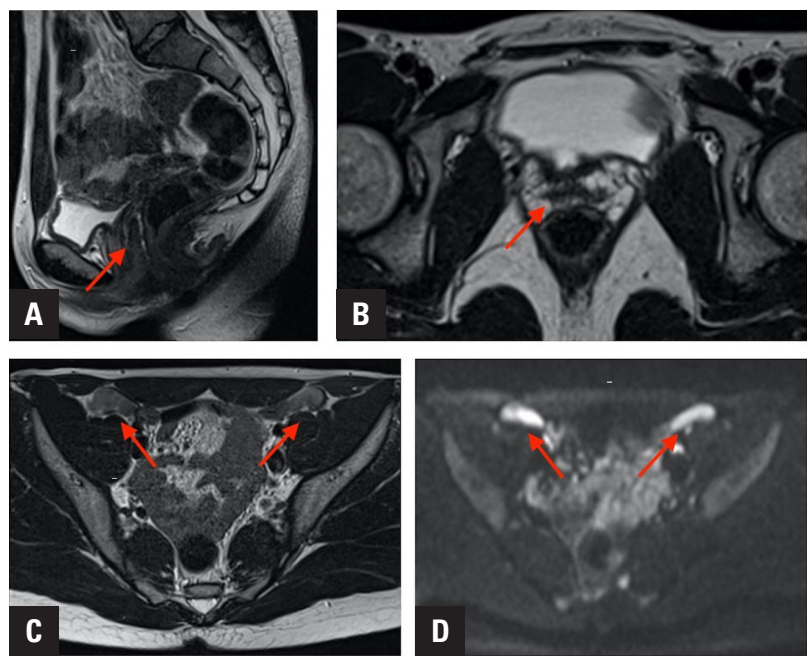

Figure 1. Sagittal (A) and axial (B) T2-weighted magnetic resonance images of lower pelvic organs. Red arrow indicates hypoplastic vagina localised between the bladder (to the front) and rectum (backwards). Axial MR cross-sections (C, D) at the level of inguinal canals. Red arrows indicate two ovoid structures exhibiting intermediate signal on T2w images and high signal intensity on diffusion-weighted images $(b=800, D)$ primarily described as reactive lymph nodes — which was consistent with history of inflammation

CAIS. It is of utmost importance to extensively inform the patient about the diagnosis and its consequences, especially regarding the elevated risk of malignant transformation in undescended testicles, because ultimately it is the patient who directs the treatment.

\section{Conflict of interest}

None declared.

\section{Funding}

No financial disclosures.

\section{References}

1. Petriczko E, Marcinkiewicz K, Słowikowska-Hilczer J, et al. Zespół częściowej niewrażliwości na androgeny - opis przypadku. Endokrynol Ped. 2014; 1: 61-68.

2. Morris JM. The syndrome of testicular feminization in male pseudohermaphrodites. Am J Obstet Gynecol. 1953; 65(6): 1192-1211, doi: 10.1016/ 0002-9378(53)90359-7, indexed in Pubmed: 13057950.

3. Quigley CA, De Bellis A, Marschke KB, et al. Androgen receptor defects: historical, clinical, and molecular perspectives. Endocr Rev. 1995; 16(3): 271-321, doi: 10.1210/edrv-16-3-271, indexed in Pubmed: 7671849.

4. Domenice S, Arnhold IJP, Costa EMF. 46, XY disorders of sexual development. [Updated 2017 May 3]. In: Feingold KR, Anawalt B, Boyce A. ed. Endotext [Internet]. Comprehensive free online endocrinology books. MDText, South Dartmouth 2000: Available on: https://www.ncbi. nlm.nih.gov/books/NBK279170/

5. Sarpel U, Palmer SK, Dolgin SE. The incidence of complete androgen insensitivity in girls with inguinal hernias and assessment of screening by vaginal length measurement. J Pediatr Surg. 2005; 40(1): 133-6; discussion 136, doi: 10.1016/j.jpedsurg.2004.09.012, indexed in Pubmed: 15868573. 